JURNAL RISET MAHASISWA AKUNTANSI (JRMA)

Volume 8, No. 1, Tahun 2020

e-ISSN : 2715 - 7016

\title{
ANALISIS PENGARUH PROFITABILITAS, STRUKTUR MODAL, KEPEMILIKAN MANAJERIAL DAN DEWAN KOMISARIS INDEPENDEN TERHADAP NILAI PERUSAHAAN
}

\author{
Alfiana Suri \\ e-mail:alfianasuri3@gmail.com \\ Retno Wulandari \\ Supami Wahyu Setiyowati \\ Program Studi Akuntansi, Fakultas Ekonomika dan Bisnis, Universitas Kanjuruhan Malang
}

\begin{abstract}
Abstrak
Pengaruh profitabilitas, struktur modal, kepemilikan manajerial dan dewan komisaris independen terhadap nilai perusahaan baik itu secara simultan dan parsial. Teknik yang digunakan dalam pengambilan sampel menggunakan metode purposive sampling karena dalam pengambilan sampel menggunakan kriteria tertentu.penelitiandilakukan dalam kurun waktu 2016-2018. Metode analisis yang digunakan regresi linier berganda dengan program SPSS 22. Hasil penelitian menunjukan bahwa secara simultan terdapat pengaruh antara profitabilitas, struktur modal, kepemilikan manajerial dan dewan komisaris independen terhadap nilai perusahaan dan secara parsial profitabilitas yang tidak memiliki pengaruh terhadap nilai perusahaan, sedangkan struktur modal, kepemilikan manajerial dan dewan komisaris independen berpengaruh siginifikan terhadap nilai perusahaan .

Kata kunci : profitabilitas, struktur modal, kepemilikan manajerial, dewan komisaris independen.
\end{abstract}

\begin{abstract}
The effect of profitability, capital structure, managerial ownership and independent board of commissioners on the company's value both simultaneously and partially. The technique used in sampling uses a purposive sampling method because in sampling it uses certain criteria. The research was conducted in the period 2016-2018. The analytical method used is multiple linear regression with the SPSS 22 program. The results of the study show that there is simultaneously an influence between profitability, capital structure, managerial ownership and independent board of commissioners on company value and partial profitability which has no influence on firm value, while capital structure, managerial ownership and independent board of commissioner have a significant effect on the value of the company.

Keywords: profitability, capital structure, managerial ownership, independent board of commissioners.
\end{abstract}

\section{PENDAHULUAN}

Perusahaan merupakan unit kegiatan produksi yang mengolah sumber daya ekonomi untuk menyediakan barang dan jasa bagi masyarakat dengan tujuan memperoleh keuntungan dan memuaskan kebutuhan masyarakat.Tujuan suatu perusahaan memaksimumkan nilai perusahaan dari sekarang, semua keuntungan yang akan diterima oleh pemegang saham di masa yang akan datang. Nilai perusahaan tercermin dari harga saham yang stabil, yang dalam jangka panjang mengalami kenaikan, semakin tinggi harga saham maka semakin tinggi pula nilai perusahaan (Sudana, 2009) . 
Meminimalisir adanya risiko pada suatu perusahaan yang tidak sesuai investor dapat dilihat dari beberapa analisis fundamental (pengaruh harga saham dimasa akan datang) seperti ROA, DER, KM, DKI. nilai pasar dari asset perusahaan di bagi dengan biaya penggantiannya nilai perusahaan (Tobins' $Q$ ) untuk membedakan saham yang memiliki nilai wajar, nilai yang terlalu tinggi dan nilai yang rendah. Tobin's $Q$ memasukan semua unsur hutang dan modal saham perusahaan, tidak hanya saham biasa dan ekuitas perusahaan saja, namun seluruh asset juga dimasukan (Weston dan Copeland 2010).

Investor membutuhkan informasi sebagai panutan ketika menanamkan dana pada suatu perusahaan. Setiap akun dalam laporan keuangan merupakan signal yang harus diinformasikan kepada investor maupun calon investor. Untuk menilai kenaikan atau penurunan nilai perusahaan dengan menilai melalui rasio pasar modal Tobins' $Q$, rasio earning (profitabiltas) yang diproksikan dengan Return On Asset (ROA), debt to equity ratio (DER). Kepemilikan manajerial (KM) dan dewan komisaris independen (DKI).

Rasio pasar modal dapat dilihat pula dari rasio profitabilitas yaitu Return On Assets (ROA), yang dapat mengukur seberapa besar kemampuan perusahaan dalam memperoleh laba baik dalam hubungannya dengan penjualan, asset maupun laba bagi modal sendiri. Rasio profitabilitas (Profitability Ratio), ini menujukan keberhasilan perusahaan di dalam menghasilkan laba (Fandini, 2013).

\section{TINJAUAN PUSTAKA}

Harga saham yang tinggi membuat nilai perusahaan juga tinggi. Memaksimalkan nilai perusahaan sangat penting bagi suatu perusahaan, karena dengan memaksimalkan nilai perusahaan berarti juga memaksimalkan kemakmuran pemegang saham yang merupakan tujuan utama perusahaan Ika dan Shidiq (2013).Menurut (Weston dan Copeland, 2010) Tobin's $Q$ menggambarkan seberapa besar perbandingan antara rasio nilai pasar saham perusahaan dengan nilai buku ekuitas peusahaan.Tobin's $Q$ juga menunjukkan seberapa jauh suatu perusahaan mampu menciptakan nilai perusahaan yang relatif terhadap jumlah modal yang dinvestasikan.

Return on Assets (ROA) menurut Kasmir (2010) merupakan rasio yang menunjukkan hasil (return) atas jumlah aktiva yang digunakan dalam perusahaan.ROA menunjukkan kemampuan manajemen bank dalam menghasilkan laba dari pengelolaan aset yang dimiliki.Semakin besar ROA suatu bank, semakin besar pula tingkat keuntungan yang dicapai bank, dan semakin baik pula posisi bank dari segi penggunaan aset.

Debt to Equity Ratio (DER) Struktur modal merupakan perbandingan antara utang dengan ekuitas, struktur modal merupakan masalah penting dalam keputusan belanja , Bentuk pembelanjaa yang permanen di dalam mencerminkan keseimbangan di antara hutang jangka panjang dengan modal sendiri sehingga sering diistilahkan dengan struktur modal (Adi Yasa, 2013).Pembelanjaan yang permanen di dalam mencerminkan keseimbangan diantara hutang jangka panjang dengan modal sendiri sehingga sering diistilahkan dengan struktur modal.

Kepemilikan manajerial menujukan adanya peran ganda seorang manajer dalam suatu perusahaan, yakin sebagai manajer dan sebagai pemegang saham.Perusahaan memberikan kesempatan kepada manajer untuk memiliki sebagian saham perusahaan.Keputusan itu dilakukan untuk mempertahankan manajer agar bertindak sesuai dengan tujuan perusahaan yang meningkatkan kesejateraan pemegang saham. Semakin besar proporsi kepemilikan manajemen dalam perusahaan maka manajemen akan berusaha lebih giat lagi untuk kepentingan pemegang saham yang notabene adalah mereka sendiri (Wibowo, 2017).

Dewan komisaris independen yang besar dapat memberikan keuntungan maupun kerugian bagi perusahaan.Keuntungan dari dewan yang besar dalam suatu perusahaan yaitu 
dapat mengelolah sumber dayanya dengan lebih baik. Pertikaran keahlian, pikiran dan informasi dalam dewan juga akan lebih luas dan bervariasi (Fitdini, 2009). Suatu perusahaan yang memiliki komisaris indepeden secara umum dipastikan mempunyai agency cost yang rendah. Hal ini dikarenakan dewan komisaris independen dipandang dapat menyediakan pengawasan dewan yang lebih baik dengan cara melakukan pengawasan independen terhadap dewan direksi.

\section{Hipotesis Penelitian:}

Menurut (Sugiono, 2014) mendefinisikan hipotesis adalah jawaban sementara terhadap rumusan masalah penelitian, dimana rumusan masalah penelitian telah dinyatakan dalam bentuk kalimat pertanyaan.Return on Assets ROA, DER, KM, dan DKI berpengaruh positif terhadap nilai perusahaanapabila, nilai ROA, DER, KM, dan DKI itu naik maka nilai perusahaantersebut juga kan ikut naik. Begitupun sebaliknya jika ROA, DER, KM, dan DKI turun maka nilai perusahaanyang akan diterima juga ikut turun.

Berdasarkan landasan teori dan hasil penelitian terdahulu maka dapat ditentukan hipotesis sebagai berikut.

H1: secara simultan ROA, DER, KM dan DKI berpengaruh terhadap nilai perusahaan.

$\mathrm{H} 2$ : secara parsial ROA berpengaruh terhadap nilai perusahaan

H3: secara parsial DER berpengaruh terhadap nilai perusahaan

H4: secara parsial KM berpengaruh terhadap nilai perusahaan

H5: secara parsial DKI berpengaruh terhadap nilai perusahaan

\section{METODE PENELITIAN}

Rancangan penelitian dengan menggunakan metode purposive sampling.Penelitian menganalisis pengaruh profitabilitas, struktur modal, kepemilikan manajerial dan dewan komisaris independen terhadap nilai perusahaan dengan menggunakan data laporan keuanganperusahaan food and beverage yang diperoleh melalui akses website www.idx.co.id.

Populasi penelitian adalah seluruh Perusahaan food and beverage yang terdaftar di Bursa Efek Indonesia (BEI) tahun 2016 hingga tahun 2018 yakni sebanyak 36 perusahaan. Sampel dimabil dengan teknik purposive judgement sampling. Setelah dilakukan eliminasi berdasarkan kriteria maka diperoleh sampel sebanyak12food and beverage.

Teknik analisis data penelitian menggunakan analisis regresi linier berganda.penelitian menggunakan analisis regresi linear berganda digunakan untuk menguji hipotesis yang menyatakan bahwa ROA, DER, KM, dan DKIsecara simultan atau parsial berpengaruh terhadap nilai perusahaan. Hubungan linier secara sistematis digambarkan dalam rumus sebagai berikut:

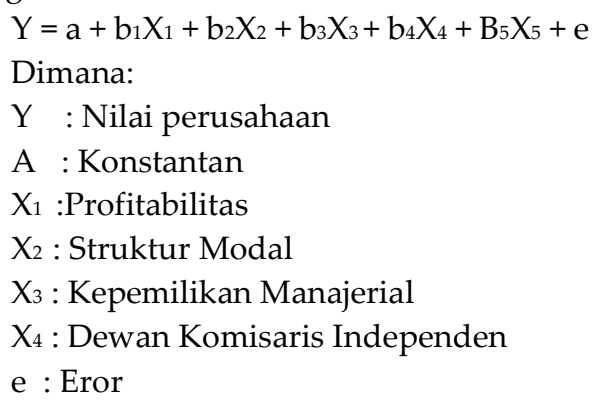

\section{a. Uji Asumsi Klasik}

1. Uji Normalitas

2. Uji Multikolinieritas 
3. Uji Autokorelasi

4. Uji Heteroskedastisitas

b. Uji Hipotesis

1. Uji Signifikansi Simultan (Uji Stastitik F)

2. Uji Parsial (uji-t)

3. Uji Koefisien Determinasi $\left(\mathrm{R}^{2}\right)$

\section{HASIL DAN PEMBAHASAN}

\section{A. PENGUJIAN ASUMSI KLASIK}

\section{Hasil Uji Normalitas}

Uji normalitas bertujuan menguji apakah model regresi, variabel pengganggu atau residual memiliki distribusi normal (Ghozali, 2011). Menguji apakah residual berdistribusi normal atau tidak, test statistik yang digunakan adalah Kolmogorov Smirnov. Normal tidaknya distribusi data dilihat dari nilai Asymp Sig (2-tailed), jika nilai Asymp Sig (2-tailed)> dari alpa 0.05 atau 5\% maka variabel pengganggu berdistribusi normal.

\section{Hasil Uji Multikolinieritas}

Menguji apakah model regresi ditemukan adanya kolerasi antar variabel independen (Ghozali, 2011). Model regresi yang baik tidak terjadi korelasi antara variabel independen agar tidak terdapat problem multikolinieritas. Untuk mengetahi ada atau tidaknya problem multikolinieritas dengan menentukan nilai VIP (Variance inflation Faktor), apabila nilai VIF $<10$ atau nilai Tolerance $>0,1$ berarti tidak terjadi multikolinieritas.

\section{Hasil Uji klasik autokorelasi}

Uji autokorelsi bertujuan menguji apakah dalam model regresi ada korelasi antara kesalahan pengganggu pada periode $t$ dengan kesalahan pengganggu pada periode sebelumnya. Dilakukan dengan uji Durbin Watson (DW), kriteria yang digunakan menurut Firdaus (2010) adalah nilai DW $=1,55-2,46$. Jika nilai Durbin Watson sesuai kriteria maka tidak terjadi autokorelasi.

\section{Hasil Uji Heteroskedastisitas}

Hasil uji asumsi klasik heteroskedastisitas dengan pendekatan Scatter Plot. Dari gambar grafik Scatter Plot menunjukkan bawah titik-titik menyebar secara acak serta tersebar baik diatas maupun dibawah angka 0 pada sumbu Y. Dengan demikian dapat disimpukan bahwa tidak terjadi Heteroskedastisitas pada model regresi.

\section{Koefisien Determinasi $\left(\mathbf{R}^{2}\right)$}

Koefisen determinasi $\left(R^{2}\right)$ pada intinya mengukur seberapa jauh kemampuan model dalam menerangkan variasi variabel dependen.Nilai Koefisensi determinasi adalah antara nol dan satu $(0<R<1)$.Semakin besar koefisen determinasi maka semakin besar variasi variabel independnya mempengaruhi variabel dependennya.atas dapat dilihat bahwa nilai $\mathrm{R}$ Square sebesar 0,347 (34,7\%) yang berarti bahwa pengaruh ROA $\left(\mathrm{X}_{1}\right)$, DER $\left(\mathrm{X}_{2}\right), \mathrm{KM}\left(\mathrm{X}_{3}\right)$ dan DKI $\left(\mathrm{X}_{4}\right)$ mampu menjelaskan variasi dari variabel nilai perusahaan (Y) sebesar 34,7\%) pada perusahaan food and beverage. Sisanya sebesar $65,3 \%$, dipengaruhi faktor lain yang tidak digunakan dalam penelitian :

$\mathrm{Y}=1,208+1,416 \mathrm{X} 1+0,309 \mathrm{X} 2+0,580 \mathrm{X} 3+0,857 \mathrm{X} 4+\mathrm{e}$

1. Nilai konstanta sebesar 1,206 , memiliki arti bahwa jika semua variabel bebas $(X)$ yakni P ROA, DER,KM dan DKI bernilai 0 (nol) dan tidak ada perubahan, maka nilai perusahaan akan bernilai 1,208 
2. Nilai koefisien regresi variabel $\mathrm{ROA}\left(\mathrm{X}_{1}\right)$ negatif 1,416 , menunjukkan bahwa variabel ROA berhubungan negatif terhadap nilai perusahaan. Artinya jika ROA mengalami kenaikan sebesar 1 persen dengan asumsi variabel bebas lainnya konstan, maka jumlah return saham akan mengalami penurunan sebesar 1,416.

3. Nilai koefisien regresi variabel DER $\left(\mathrm{X}_{2}\right)$ positif 0,309 , menunjukkan bahwa variabel PBV berhubungan positif terhadap nilai perusahaan. Artinya jika DER mengalami kenaikan sebesar 1 persen dengan asumsi variabel bebas lainnya konstan, maka jumlah nilai perusahaan akan mengalami kenaikan sebesar 0,309.

4. Nilai koefisien regresi variabel $\mathrm{KM}\left(\mathrm{X}_{3}\right)$ positif 0,580 , menunjukkan bahwa variabel DKI berhubungan positif terhadap nilai perusahaan. Artinya jika KM mengalami kenaikan sebesar 1 persen dengan asumsi variabel bebas lainnya konstan, maka jumlah nilai perusahaan akan mengalami kenaikan sebesar 0,580 .

5. Nilai koefisien regresi variabel DKI $\left(\mathrm{X}_{4}\right)$ positif 0,857 , hal ini menunjukkan bahwa variabel DKI berhubungan positif terhadap nilai perusahaan. Artinya jika DER mengalami kenaikan sebesar 1 persen dengan asumsi variabel bebas lainnya konstan, maka jumlah nilai perusahaan akan mengalami kenaikan sebesar 0,857 .

\section{PEMBAHASAN}

1. Hasil uji statistik F dapat dijelaskan ROA, DER, KM, DKI berepengaruh secara simultan terhadap nilai perusahaan. Naik turunnya nilai perusahaan dipengaruh oleh perubahan profitabilitas, struktur modal, kepemilikan manajerial dan dewan komisaris independen sisanya di pengaruhi oleh variabel lain yang tidak diteliti. Hal tersebut mengindikasiakan bahwa variabel profitabilitas, struktur modal, kepemilikan manajerial dan dewan komisaris independen memberi pengaruh yang cukup besar terhadap nilai perusahaan, karena jika penggunaan hutang semakin banyak, semakin besar pula kepercayaan kreditur terhadap perusahaan karena perusahaan mampu melunasi hutangnya sesuai dengan jangka waktu yang telah di tentukan, dengan mengamati hal tersebut maka investor akan semakin percaya sehingga para investor menanamkan modal mereka pada perusahaan tersebut, dengan demikian maka nilai perusahaan akan semakin baik. Profitabilitas merupakan gambaran tentang seberapa besar kemampuan perusahaan akan memengaruhi nilai perusahaan. Hasil penelitian mendukung penelitian yang dilakukan oleh Prima Roma, dkk (2018) yang membuktikan bahwa profitabilitas, struktur modal, ukuran perusahaan dan modal intelektual berpengaruh secara bersama-sama terhadap nilai perusahaan, Arizky, dkk (2019) hasil penelitian ini menunjukan bahwa keputusan pendanaan dan kebijakan dividen berpengaruh siginifikan terhadap nilai perusahaan.

2. Hasil analisis menunjukkan Return On Asset, tidak berpengaruh terhadap nilai perusahaan. Dengan demikian $\mathrm{H}_{2}$ yang menyatakan profitabilitas pengaruh terhadap nilai perusahaan tidak dapat diterima.Tidak berpengaruhnya ROA pada nilai perusahaan dapat diakibatkan oleh ketidakpercayaan investor atas informasi keuangan yang disajikan oleh emiten. Didukung oleh tidak berpengaruhnya reputasi auditor, yang artinya investor tidak mempertimbangkan reputasi auditor ketika akan melakukan investasi pada perusahaan.

3. Hasil analisis menunjukkan DER berpengaruh terhadap nilai perusahaan. Pengujian hipotesis ini dapat diartikan bahwa utang yang dilakukan oleh perusahaan untuk melakukan ekspansi usaha akan meningkatkan harga saham dari perusahaan tersebut, sehingga nilai perusahaan meningkat. Hasil penelitian ini sesuai dengan penelitianSudiani dan Darmayanti (2016). 
4. Hasil analisis menunjukkan kepemilikan manajerial berpengaruh terhadap nilai perusahaan. Jika dilihat dari arah hubungannya memiliki pengaruh artinya semakin tinggi jumlah saham yang dimiliki oleh pihak manajemen perusahaan maka semakin tinggi pula nilai perusahaan.Hasil penelitian ini sesuai dengan penelitianSofyaningsih dan Hardiningsih (2011) membuktikan bahwa kepemilikan manajerial berpengaruh terhadap nilai perusahaan.

5. Berdasarkan penguji hipotesis, dapat dijelaskan DKI berpengaruh terhadap nilai perusahaan.Dewan komisaris independen memiliki pengaruh terhadap kinerja manajemen agar lebih memaksimalkan kinerjanya dengan pengawasan yang lebih efektif. Hasil penelitian mendukung penelitiannya Perdana dan Raharja (2014).

\section{KESIMPULAN}

Berdasarkan pengujian dan penjelasan disimpulkan bahwa bahwa secara simultan ROA, DER, KM, DKI berpengaruh terhadap nilai perusahaan.Sedangkan secara parsial ROA tidak berpengaruh terhadap nilai perusahaan, SER, KM, DKI secara parsial berpengaruh terhadap nilai perusahaan.

\section{SARAN}

Sebaiknya peneliti selanjutnya melakukan penelitian pada sektor yang berbeda dengan jumlah sampel yang lebih banyak dan metode analisis yang berbeda. Selain itu peneliti merubah atau menambah variabel-variabel pengukuran lainnya sehingga dapat memperkuat hasil peneliti selanjutnya.

\section{DAFTAR PUSTAKA}

Adi Yasa, Dkk. 2013.Pengaruh Penendidikan Matematika Realistik Dan Gaya Kognitif Terhadap Prestasi Belajar Matematika Siswa. Singaraja: Universitas Pendidikan Ganesha. (E-Jurnal Program Pascasarjana Universitas Pendidikan Ganesha Program Studi Matematika, Vol. 2 Tahun 2013).

Fitdini. 2009. Pengaruh Corporate Governance Terhadap Financial Distress (Studi Pada Perusahaan Manufaktur Yang Listed Di Bej). Jkp Xi Hal.236-247.

Ghozali, I. (2016). Aplikasi Analisis Multivariate dengan Program IBM SPSS 23. Edisi 8. Semarang: Badan Penerbit Universitas Dipenogoro.

Ghozali, Imam 2011. Aplikasi Analisis Multivariate Dengan Program Spps .Semarang: Badan Penerbit Universitas Diponegoro.

Ika Dan Shidiq. 2013. Pengaruh Profitabilitas Terhadap Nilai Perusahaan (Kebijakan Dividen d an Kesempatan Investasi Sebagai Variable Mediasi). Jurnal Manajemen Unud, Vol. 4(12). 2015, H : 4477-4500.

Kasmir, 2010.Analisis Profitabilitas Dalam Menilai Kinerja Keuangan. Vol. 2 No 2,2018.Hlm 278293.

Perdana, R. S., \& Raharja. 2014. Analisis Pengaruh Corporate Governance terhadap Nilai Perusahaan. Diponegoro Journal of Accounting. Vol. 3, No. 3, Tahun 2014: 1-13. 
Alfiana Suri, Analisis Pengaruh Profitabilitas, Struktur Modal, Kepemilikan Manajerial Dan Dewan Komisaris Independen Terhadap Nilai Perusahaan

Sofyaningsih, Sri Pacawati Hardiningsih (2011). Struktur Kepemilikan, Kebijakan Dividen, Kebijakan Utang Dan Nilai Perusahaan Ownership Structure, Dividend Policy And Debt Polcy And Firm Value. Jurnal manajemen

Sudana, I Made. 2009. Manajemen Keuangan :Teori Dan Praktek. Surabaya : Airlangga University.

Sudiani, N. K., \& Darmayanti, N. P. (2016). Pengaruh Profitabilitas, Likuiditas, Pertumbuhan, Dan Investment Opportunity Set Terhadap Nilai Perusahaan . E-Jurnal Manajemen Unud, Vol. 5, No.7: 4545-4547.

Sugiyono. 2015. Metode Penelitian Kombinasi (Mix Methods). Bandung: Alfabeta

Wayan Firdaus. (2010). Penerapan Algoritma Genetika Pada Sistem Rekomendasi Wisata Kuliner.Jurnal Ilmiah Kursor, Vol.5, No. 4, hlm 205- 211.

Weston, J. Feed Dan Thomas E. Copeland. 2010. Manajemen Keuangan. Jakarta: Binarupa Aksara.

Wibowo. 2017. Manajemen Kinerja. Edisi Kelima. Depok Pt.Raja Grafindo Persada. 